\title{
Üst Üriner Sistem Toplayıcı Sistem Tümörü Cerrahisinde Lenfadenektomi Gerekli mi?
}

\section{Is Lymphadenectomy Necessary in the Surgical Treatment of Upper Urinary Tract Urothelial Carcinoma?}

\author{
Dr. Yakup Kordan, Dr. Onur Kaygısız \\ Uludağ Üniversitesi Tıp Fakültesi, Üroloji Anabilim Dalı, Bursa, Türkiye
}

\section{Özet}

Üst üriner sistem değişici hücreli kanserinde (DHK) lenf nodu diseksiyonunun (LND) yeri halen tartışmalıdır. Bu derlemede güncel çalışmalar ışığında bu konudaki mevcut klinik yaklaşımın ortaya konmas amaçlandı. Günümüzde görüntüleme yöntemleri ile halen yeterli doğrulukta lenf nodu tutulumu değerlendirilmesi yapılamamaktadır. LND lenf nodu tutulumunu göstermede altın standarttır. Lenf tutulumunun tespit edilmesi sağkalım hakkında bilgi sağlamakla birlikte LND yapılmasının sağkalım üzerine etkisi tartışmalıdır. T1 tümörlerde sağkalıma katkısı olmadığını gösteren birçok çalışma mevcut olmakla birlikte kas invazif veya lokal ileri evre hastalıkta (T2-T4) ve işlem öncesi veya sırasında fark edilen lenf nodu tutulumu olan hastalarda tüm rejyonel bölgeyi içine alacak şekilde LND yapılmasının sağkalımı olumlu etkilediğini gösteren birçok retrospektif çalışma mevcuttur. Laparoskopik nefroüreterektomi T1-T2N0 tümörlerde açık cerrahiye benzer komplikasyon ve onkolojik sonuçlara sahiptir ve eșit etkinlikle kullanılabilir. Invazıf ve büyük (T3/T4 ve /veya $\mathrm{N}+/ \mathrm{M}+$ ) tümörlerde ise aksi ispatlanana dek laparoskopik cerrahi kontraendike kabul edilmektedir. (Üroonkoloji Bülteni 2014;13:99-102) Anahtar Kelimeler: Lenfadenektomi, neoplasmlar, üreteral; renal pelvis, karsinom, değişici hücreli; renal pelvis

\begin{abstract}
Summary
The role of lymph node dissection (LND) in the treatment of upper urinary tract transitional cell carcinoma (TCC) is still controversial. In this review, we aimed to put forth the present clinical approach regarding this issue in the light current literature. Nowadays, the assessment of lymph node involvement cannot be done accurately by current imaging modalities. LND is a gold standard in detecting lymph node involvement. Although lymph node involvement provides information about survival, the contribution of LND to survival is also controversial. Despite some studies reporting no contribution of LND to survival among T1 patients, many retrospective studies have shown an increase in survival among muscle-invasive, locally invasive and lymph node-positive patients when LND was performed completely, removing all regional lymph nodes. Laparoscopic nephroureterectomy has similar oncological and complication results as open surgery and can be used equivalently in T1T2/N0 tumors. However, laparoscopic nephroureterctomy until proven otherwise is contraindicated in the treatment of invasive or large (T3-T4 and/or $\mathrm{N}^{+} / \mathrm{M}^{+}$) tumours. (Bulletin of Urooncology 2014;13:99-102)
\end{abstract}

Key Words: Lymphadenectomy, neoplasms, ureteral; renal pelvis, carcinoma, transitional cell, renal pelvis

\section{Giriş}

Üst üriner sistemin değişici hücreli kanseri (DHK) nadir görülen kanserlerinden olup tüm ürotelyal kanserlerin $\% 5^{\prime}$ ini oluşturmakdır. Tanı anında üst üriner sistem DHK mesanenin DHK'lerine göre daha ileri evrededir (1). Tanı anında hastaların sadece \%30'u kasa invaze olup \%75'e yakını da yüksek gradelidir (2). Artan grade ve evre ile birlikte lenf nodu metastaz oranı da artmaktadır. Roscigno ve ark. (2) T1, T2, T3-4 hastalarda sırasıyla $\% 6, \% 16, \% 35$ lenf nodu tutulumu saptamış ve LN tutulumu olan hastaların patolojisinde hastaların \%94'ünde yüksek gradeli DHK bildirmişlerdir. Kondo ve ark. (3) da benzer şekilde Ta-1, $\mathrm{T} 2, \mathrm{~T} 3, \mathrm{~T} 4$ tümörlerde LN tutulumunu sırasıyla $\% 0, \% 5, \% 24$,
\%84 olarak bildirmişlerdir. Kas tutulumu olan mesanenin DHK tedavisinde lenf nodu diseksiyonunun (LND) gerekliliği ve sınırları tanımlanmışken üst sistem DHK tedavisinde LND’nin gerekliliği ve sınırları için tam bir görüşbirliği yoktur (4). Üst sistem DHK tedavisinde yapılan nefroüreterektomi sırasında LND hastaların ancak \%50'sinde yapılmakta ve çoğu vakada da sınırlı yapılmaktadır $(2,3)$.

Mesaneden farklı olarak üst üriner sistem tümörlerinde LND bölgesi tümörün üreterde yerleşim yerine göre değişkenlik göstermektedir. Genel olarak, üreterin lenfatik drenajı üreterin kanlanmasına paralel seyreder. Renal pelvisin lenfatik drenajı hiler bölgede renal lenfatiklerle birleşerek en sık interaortakaval 
nodlar, sağda parakaval ve retrokaval nodlara, solda paraaortik ve preaortik nodlara drene olmaktadır (5). Vakaların üçte birinde ise lenfatik drenaj direk torasik kanala drene olmaktadır (5). Üst ve orta üreter sağda retrokaval ve interaortakaval lenf nodlarına, solda paraaortik lenf nodlarına drene olurken alt üreter öncellikle kommon iliak, obturator, eksternal ve internal iliak lenf nodları ve presakral lenf nodlarına drene olur $(3,6)$. LND sınırlarına karar vermede üst üriner sistem DHK'nın yerleştiği yer ve buranın lenfatik drenaj bölgelerinin bilinmesi önemli rol oynamaktadır. Lenf nodu tutulumunu göstermekte LND altın standarttır. Lenf nodu tutulumunu LND yapmadan öngörmede bilgisayarlı tomografi ve manyetik rezonans görüntüleme gibi görüntüleme yöntemleri yeterli olamamaktadır $(7,8,9)$. PET-BT ile yapılan incelemelerde de hastaların \%20 ile \%50'sinde lenf nodu tutulumu tanısı konamamaktadır $(7,8)$. Konda ve ark. LND sonrası veya takipte lenf nodu pozitifliği gelişen toplam 42 hastada ilk değerlendirmede 19 hastada LN tutulumu saptayamadıklarını bildirmişlerdir (9).

Roscigno ve ark. (10) üst üriner sistem $\mathrm{DHK}^{\prime} \mathrm{da}$ nefroüreterektomi+LND sonrası doğru bir lenf nodu değerlendirmesi yapılabilmesi için en az 8 nod çıkarılması gerektiğini bildirmişlerdir. Bu çalışmalarında, LND'de en az 8 lenf nodu çıkarılması durumunda LN invazyonunu saptamada \%75 oranında doğru değerlendirme yapıldığını, bu sayının 13 olması durumunda doğru değerlendirmenin \%90'a çıtığını raporlamışlardır. Bu çalışmada bile ortanca 5 lenf nodu çıkarılabilmiş ve hastaların ancak \%50'sinde LND yapıldığı da bildirilmiştir (10).

Üst üriner sistem DHK cerrahi tedavisinde nefroüreterektomi ile birlikte LND yapılması doğru bir LN tutulumu değerlendirilmesi ve evreleme yapma olanağı sağlar. Mesanenin DHK'sında gösterildiği gibi genişletilmiş LND üst üriner sistemin $D H K^{\prime}$ sında da daha iyi evreleme ile birlikte sınırlı nodal hastalıkta kür sağlayabilir. LND’nin hastalığın tedavisi üzerine sağladığı yararı öngörmede hastalıksız sağkalım (HS) ve kanser spesifik sağkalım (KSS) gibi parametreler kullanılmaktadır. Literatürde üst üriner sistem DHK'da lenf nodu tutulumu varlığının 5 yıllık KSS'yi bağımsız olarak azalttığı multivaryant analizlerde gösterilmiştir $(11,12)$. Bolenz ve ark.'nın (12) çalışmasında LN tutulumu varlığının rekürensi 2,4 kat, kansere bağlı ölümü de 2,44 kat arttırdığı rapor edilmiştir. Kondo ve ark. (3) ise LN tutulumu varlığında 2 ve 5 yıllık KSS'yi sırasıyla \%26,3 ve \%15,5 olarak bildirmişlerdir. Abe ve ark. (13) LND yapılmayan 146 hasta ile LND yapılan ve pN0 olan 139 hastayı karşılaştırdıkları 312 hastalık serilerinde LND yapılmasını kanser spesifik sağkalım (KSS) açısından bağımsız değişken olarak anlamlı bulmuş ve bunu LND tedavi edici etkisine bağlı olabileceğini bildirdirmişlerdir. Ancak, bu çaılşmada patolojik olarak lenf nodu tutulumu olan hastalar $(\mathrm{pN}+)$ ve lenf nodu tutulumu olmayan hastalar ( $\mathrm{pN0}$ ) LND grubuna birlikte dahil edilmemiş ayrı ayrı alt gruplar halinde LND yapılmayan hastalarla ( $\mathrm{pNx}$ ) karşılaştırılmıştır. LND yapılmayan hastalarda da lenf nodu tutulumu olan hastalar olabileceği için bu çalışmayla LND'nin KSS üzerine etkisi için gerçek bir çıkarım yapılması tartışmalı kalmıştır. Bu çalışmanın akşine, Miyake ve ark. (14) da 72 hastalık serilerinde LND uygulanan 35 hasta ile uygulanmayan hastalar arasında sağkalım farkı bulunmadığını bildirmişlerdir (Tablo 1). Lughezzani ve ark. (15) da SEER verilerini kullandıkları 2824 vaka içeren ortanca 43 aylık takip yapılan çalışmalarında 5 yıllık KSS'ı LND yapılmayan ve LND yapılan ancak lenf nodu metastazı olmayan hastalarda benzer bulmuşlardır. Bu hastalarda KSS sırasıyla \%77,8 ve \%81,2 olarak bildirilmiştir. Bu çalışmanın verileri gözden geçirildiğinde, LND yapılmayan grupta $L N+$ hastaların da olabileceği göz önüne alındığında LND yapılmayan grupla LND yapılan pN0 hastalara benzer KSS'lerin bulunması, LND'nin LN+ hastalarda potansiyel terapötik rolünün olabileceğini düşündürmektedir.

Roscigno ve ark.'nın (2) 1130 hastalık çalışmasında 5 yıllık KSS'nin lenf nodu pozitifliğinde $\% 77^{\prime}$ den $\% 35^{\prime}$ e düştüğü, pT2-4 hastalıkta ise bu oranın \%70'ten \%33'e düştüğü bildirilmiştir. pT1 hasta grubunda LND multivariate analizde KSS ve HS üzerinde anlamlı değişken olarak saptanmazken, pT2-4 hastalarda KSS ve HS için anlamlı bir değişken olarak saptanmıştır (Tablo 1) (2). Ayrıca aynı grubun başka bir çalışmasında da kas invaziv hastalıkta (pT2-T4) LND'nin HS ve KSS için bağımısız olduğu tekrar bildirilmiştir (Tablo 1) (16). Bu çalışmada, HS ( $p>0,01, H R=0,31)$ ve KSS $(p=0,004$, $H R=0,475)$ de anlamlı bir iyileşme gözlenmesi için LND ile çıkarılması gereken LN sayısı multivaryant analizde en az 6 olarak saptanmıştır (16). Benzer şekilde, Brausi ve ark. (17) kas invaziv (pT2-T4) üst üriner sistem DHK içeren 82 hastalık serilerinde LND'nin hem HS hem de KSS'yi olumlu etkileyen bağımısız değişken olduğunu saptamışlardır (Tablo 1). LND yapılan ve yapılmayan hasta grubunda HS sırasıyla \%64,3 ile $\% 46,3$ iken KSS sırasıyla \%81,6 ile \%44,8 olarak bildirmişlerdir.

\begin{tabular}{|c|c|c|c|c|c|c|c|c|}
\hline \multirow[t]{2}{*}{ Çalışma } & \multirow{2}{*}{$\begin{array}{l}\text { Hasta } \\
\text { sayısı }\end{array}$} & \multirow[t]{2}{*}{ Evre } & \multirow{2}{*}{$\begin{array}{l}\text { Median takip } \\
\text { süresi }\end{array}$} & \multicolumn{2}{|c|}{ LND } & \multicolumn{2}{|c|}{5 yıllık KSS } & \multirow[t]{2}{*}{$\mathbf{P}$} \\
\hline & & & & VAR & YOK & LND + & LND - & \\
\hline Roscigno ve ark. (2) & 1130 & pT1-4 & 45 & $\begin{array}{l}552 \\
(\% 49)\end{array}$ & $578(\% 51)$ & $\% 66$ & $\% 69$ & NS \\
\hline Roscigno ve ark. (16) & 132 & pT2-4 & & $95(\% 72)$ & $37(\% 28)$ & $\% 67$ & $\% 40$ & 0,02 \\
\hline Kondo ve ark. (3) & 169 & pT1-T4 & 37 & $\begin{array}{l}81 \\
(\% 48)\end{array}$ & $\begin{array}{l}88 \\
(\% 52)\end{array}$ & & & NS \\
\hline Brausi ve ark. (17) & 82 & pT2-4 & 43 & $40(\% 48,8)$ & $42(\% 51,2)$ & $\% 82$ & $\% 45$ & 0,007 \\
\hline Miyake ve ark. (14) & 72 & pT1-4 & & $\begin{array}{l}35 \\
(\% 49)\end{array}$ & $\begin{array}{l}37 \\
(\% 51)\end{array}$ & $\% 58$ & $\% 50$ & NS \\
\hline
\end{tabular}


Kondo ve ark. (18) LND uygulanmış 81 [ 45 hastaya komplet (tüm rejyonel lenf nodları=Primer lenfatik drenajın \%30'unun olduğu lenfatik bolgelerin çıkarılması), 36 hastaya inkomplet LND] ve LND uygulanmamış 88 hastalık serilerinde bütün hastalar dahil (pT1-4) edildiğinde LND yapılmasını sağkalımda etkili saptamazken subgrup analizde pT3 ve üzeri hastalığı olanlarda komplet LND yapılmasının bağımsız değişken olarak KSS'yi arttırdığını saptamışlardır (Tablo 1). Bu çalışmanın sonunda lokal ileri hastalıkta komplet LND yapılması önerilmektedir. Bu çalışmanın sonuçları çıkarılan lenf nodu sayısından çok komplet bir LND yapılmasının sağkalım üzerinde olumlu katkı sağladığını vurgulamaktadır.

Literatürde üst üriner sistem DHK cerrahi tedavisi ile ilgili çalışmalarda nefroüreterektomiye ek olarak LND yapılması oranı genelde $\% 50$ civarındadır $(2,3,14,17)$. ABD'de 10 yıllık süreçte LND yapılmama oranı yaklaşık \%50 azalmıştır, bu oran 1988-1994 yılları ile 2000-2004 yılları karşılaştıııldığında $\% 32,7^{\prime}$ den $\% 16,4^{\prime}$ e düşmüştür (15). Bu dönüşümden LND'nin sağladığı yararın ve kimlere ne genişlikte yapılması gerektiğinin net ortaya konmamasının yanı sıra cerrahisinin zor oluşu ve minimal invazif cerrahiler olan laparoskopi ve robotik cerrahinin yaygın kullanılmaya başlanması sorumlu olabilir. Laparoskopik ve robotik olarak üst üriner sistem DHK tedavisinde nefroüreterektomi+mesaneden kuf eksizyonu yapılabilmesi ve bu tekniklerin daha kısa hastanede yatış süresi, daha az postoperatif ağrı gibi avantajlar sağlaması hem hastalar hem de hekimler tarafından daha fazla tercih edilmesine yol açmaktadır. Laparoskopik nefroüreterektomi+LND tecrübe gerektirmektedir. Abe ve ark. (19) yayınladıkları 41 hastalık serilerinde LND ile ortanca 10 lenf nodu çıkardıklarını ve belirgin komplikasyon gelişmediğini bildirmişlerdir. Yakın zamanda yapılan sistematik bir derlemede üst üriner sistem DHK tedavisinde laparoskopik ve açık nefroüreterektomi karşılaştııılmış ve laparoskopinin onkolojik ve komplikasyon oranlarının açık cerrahiye benzer olduğu bildirilmiştir (20). Bu makalede laparoskopi yapılanlarda açık cerrahiye göre 5 yıllık KSS oranının \%9 daha iyi, mesane rekürensinin \%17 daha az ve genel rekürens oranının da \%15 daha az ortaya çıktığı bildirilmiştir. Ne var ki, 2 yıllık KSS, 5 yıllık genel sağkalım, metastazsızlık oranları ve rekürrensiz sağkalım oranları arasında istatistiksel fark saptanmamıştır. Bu derlemede literatürdeki serilerde laparoskopik nefroüreterektomi yapılanlarda LND gerektiğinde LND'ye kısıtlı yapılmış ya da açık cerrahiye geçildiği bildirilmiştir. Mevcut veriler laparoskopik nefroüreterektominin güvenle tercih edilebilecek bir yöntem olmakla birlikte özellikle LND yapılması gerektiğinde yeterli deneyim yoksa potansiyel fayda görecek hastalarda açık LND'ye geçilmesinden kaçınmamak gerektiğini düşündürmektedir. Eldeki verilerin yetersiz olması nedeniyle Avrupa Üroloji Birliği Kılavuzları'nda da (EAU guidelines on urethelial carcinomas of the upper urinary tract) laproskopik nefroüreterektomi için "T1-T2N0 tümörlerde açık cerrahiye benzer etkinlikle kullanılabilir. İnvazıf ve büyük (T3/T4 ve /veya $\mathrm{N}+/ \mathrm{M}+$ ) tümörlerde ise aksi ispatlanana dek laparoskopik cerrahi kontraendike kabul edilmelidir" ibaresi yer almaktadır.

\section{Sonuç}

Günümüzde halen LND yeri tam olarak belirlenmemiştir. LND lenf nodu tutulumunu göstermede en hassas yöntem olup görüntüleme yöntemleri ile halen yeterli doğrulukta lenf nodu tutulumu değerlendirilmesi yapılamamaktadır. Mevcut literatür kas invazyonu olmayan üst üriner sistem $\mathrm{DHK}$ 'sında LND'nin sağkalıma etkisi olmadığını ancak kas invazyonu olan veya lokal ileri evrede ise LND'nin HS ve KSS'ye olumlu etkisi olduğunu düşündürmektedir. LND yaparken DHK'nın toplayıcı sistemdeki yerine göre diseksiyon alanı belirlenmelidir. Lenf tutulumunu doğru değerlendirmek için LND sırasında en az 8 lenf nodu çıkarılması gereklidir. Sağkalımı arttırmak için en az 6 lenf nodunun ve mümkünse de tüm rejyonel lenf nodlarının çıkarılması önerilmektedir. Son çalışmalar lenf nodu sayısından çok şablon şeklinde ve komplet (primer lenf drenajının \%30'unun olduğu lenf drenajı sahası) LND yapılmasının lenf nodu sayısından daha önemli olduğunu düşündürmektedir. Laparoskopik nefroüreterektomi düşük komplikasyon oranı ve karşılaştırılabilir onkolojik sonuçlarıyla T1-T2NO tümörlerde uygulanabilir bir yöntem gibi görünmektedir. Invazıf ve büyük (T3/T4 ve /veya $\mathrm{N}+/ \mathrm{M}+$ ) tümörlerde ise aksi ispatlanana dek laparoskopik cerrahi kontraendike kabul edilmelidir.

\section{Kaynaklar}

1. Jemal A, Siegel R, Ward E, Murray T, Xu J, Thun MJ. Cancer statistics, 2007. CA Cancer J Clin 2007;57:43-66

2. Roscigno $M$, Shariat $S F$, Margulis $V$, Karakiewicz $P$, Remzi $M$, Kikuchi $E$, Langner $C$, Lotan $Y$, Weizer A, Bensalah K, Raman JD, Bolenz C, Guo CC, Wood CG, Zigeuner R, Wheat J, Kabbani W, Koppie TM, $\mathrm{Ng} \mathrm{CK}$, Suardi N, Bertini R, Fernández MI, Mikami S, Isida M, Michel MS, Montorsi F. Impact of lymph node dissection on cancer specific survival in patients with upper tract urothelial carcinoma treated with radical nephroureterectomy. J Urol 2009;181:2482-2489.

3. Kondo T, Nakazawa H, Ito F, Hashimoto Y, Toma H, Tanabe K. Primary site and incidence of lymph node metastases in urothelial carcinoma of upper urinary tract. Urology 2007;69:265-269.

4. Witjes JA, Compérat E, Cowan NC, De Santis M, Gakis G, Lebret T, Ribal MJ, Van der Heijden AG, Sherif A. EAU guidelines on muscleinvasive and metastatic bladder cancer: summary of the 2013 guidelines. Eur Urol 2014;65:778-792.

5. Assouad J, Riquet M, Foucault C, Hidden G, Delmas V. Renal lymphatic drainage and thoracic duct connections: implications for cancer spread. Lymphology 2006;39:26-32.

6. Anderson JK, Kabalin JN, Cadeddu JA. SurgicalAnatomy of theRetroperitoneum, Adrenals, Kidneys, andUreters. CampbellWalshUrology 9th Edition Wein AJ, Kavoussi LR,Novick AC et al.Elsevier; 2009. sayfa 32-38.

7. Jensen TK, Holt P, Gerke O, Riehmann M, Svolgaard B, Marcussen $\mathrm{N}$, Bouchelouche K. Preoperative lymph-node staging of invasive urothelial bladder cancer with 18F-fluorodeoxyglucose positron emission tomography/computed axial tomography and magnetic resonance imaging: correlation with histopathology. Scand J Urol Nephrol 2011;45:122-128.

8. Swinnen G, Maes A, Pottel H, Vanneste A, Billiet I, Lesage K, Werbrouck P. FDG-PET/CT for the preoperative lymph node staging of invasive bladder cancer. Eur Urol 2010;57:641-647.

9. Scolieri MJ, Paik ML, Brown SL, Resnick MI. Limitations of computed tomography in the preoperative staging of upper tract urothelial carcinoma. Urology 2000;56:930-934.

10. Roscigno $M$, Shariat SF, Freschi $M$, Margulis $V$, Karakiewizc $P$, Suardi N, Remzi M, Zigeuner R, Bolenz C, Kikuchi E, Weizer A, Bensalah K, Sagalowsky A, Koppie TM, Raman J, Fernández M, Ströbel P, Kabbani W, Langner C, Wheat J, Guo CC, Kassouf W, Haitel A, Wood CG, Montorsi F. Assessment of the minimum number of lymph nodes needed to detect lymph node invasion at radical nephroureterectomy in patients with upper tract urothelial cancer. Urology 2009;74:1070-1074. 
11. Novara G, De Marco V, Gottardo F, Dalpiaz O, Bouygues V, Galfano A, Martignoni G, Patard JJ, Artibani W, Ficarra V. Independent predictors of cancer-specific survival in transitional cell carcinoma of the upper urinary tract: multi-institutional dataset from 3 European centers. Cancer 2007; 110:1715-1722

12. Bolenz $C$, Shariat SF, Fernandez MI, Margulis $\mathrm{V}$, Lotan $\mathrm{Y}$, Karakiewicz P, Remzi M, Kikuchi E, Zigeuner R, Weizer A, Montorsi F, Bensalah K, Wood CG, Roscigno M, Langner C, Koppie TM, Raman JD, Mikami $S$, Michel MS, Ströbel P. Risk stratification of patients with nodal involvement in upper tract urothelial carcinoma: value of lymphnode density. BJU Int 2009;103:302-306.

13. Abe $T$, Shinohara $N$, Harabayashi $T$, Sazawa A, Ishikawa $S$, Kubota K, Matsuno Y, Osawa T, Shibata T, Shinno Y, Kamota S, Minami K, Sakashita S, Takeuchi I, Kumagai A, Mori T, Togashi M, Nonomura K. The role of lymph-node dissection in the treatment of upper urinary tract cancer: a multi-institutional study. BJU Int 2008;102:576-580.

14. Miyake H, Hara I, Gohji K, Arakawa S, Kamidono S. The significance of lymphadenectomy in transitional cell carcinoma of the upper urinary tract. Br J Urol 1998;82:494-498.

15. Lughezzani G, Jeldres C, Isbarn H. A critical appraisal of the value of lymph node dissection at nephroureterectomy for upper tract urothelial carcinoma. Urology 2010;7:118-124.
16. Roscigno M, Cozzarini C, Bertini R, Scattoni V, Freschi M, Da Pozzo LF, Briganti A, Gallina A, Capitanio U, Colombo R, Giorgio G, Montorsi F, Rigatti P. Prognostic value of lymph node dissection in patients with muscle-invasive transitional cell carcinoma of the upper urinary tract. Eur Urol 2008;53:794-802.

17. Brausi MA, Gavioli M, De Luca G, Verrini G, Peracchia G, Simonini G, Viola M. Retroperitoneal lymph node dissection (RPLD) in conjunction with nephroureterectomy in the treatment of infiltrative transitional cell carcinoma (TCC) of the upper urinary tract: impact on survival. Eur Urol 2007;52:1414-1418.

18. Kondo T, Nakazawa H, Ito F, Hashimoto $Y$, Toma H, Tanabe K. Impact of the extent of regional lymphadenectomy on the survival of patients with urothelial carcinoma of the upper urinary tract. J Urol 2007; 178:1212-1217.

19. Abe T, Harabayashi T, Shinohara N, Sazawa A, Maruyama S, Sasaki $\mathrm{H}$, Nonomura K. Outcome of regional lymph node dissection in conjunction with laparoscopic nephroureterectomy for urothelial carcinoma of the upper urinary tract. J Endourol 2011;25:803-807.

20. Ni S, Tao W, Chen Q, Liu L, Jiang H, Hu H, Han R, Wang C. Laparoscopic versus open nephroureterectomy for the treatment of upper urinary tract urothelial carcinoma: a systematic review and cumulative analysis of comparative studies. Eur Urol 2012;61:1142-1153. 